\title{
A Low Profile Ultrawide Band Monopole Antenna for Wearable Applications
}

\author{
Srinivas Doddipalli, Ashwin Kothari, and Paritosh Peshwe \\ Department of ECE, Visvesvaraya National Institute of Technology (VNIT), Nagpur 440010, India \\ Correspondence should be addressed to Srinivas Doddipalli; srinivas.mre@gmail.com
}

Received 24 April 2017; Revised 12 July 2017; Accepted 18 July 2017; Published 17 August 2017

Academic Editor: Miguel Ferrando Bataller

Copyright (C) 2017 Srinivas Doddipalli et al. This is an open access article distributed under the Creative Commons Attribution License, which permits unrestricted use, distribution, and reproduction in any medium, provided the original work is properly cited.

\begin{abstract}
A low profile pentagonal shaped monopole antenna is designed and presented for wearable applications. The main objective of this paper is to design a miniaturized ultrawide band monopole planar antenna which can work efficiently in free space but also on the surface of the human body. The impact of human tissues on antenna performance is explained using the proposed pentagonal monopole antenna. The antenna is designed with a pentagonal radiator and a matched feed line of 50 ohm and square slots are integrated on defected ground of FR4 substrate with a size of $15 \mathrm{~mm} \times 25 \mathrm{~mm}$ to achieve ultrawide band (UWB) performance in free space and human proximity. This overall design will enhance the antenna performance with wide bandwidth ranging from $2.9 \mathrm{GHz}$ to $11 \mathrm{GHz}$. Specific absorption rate (SAR) of the proposed antenna on dispersive phantom model is also measured to observe the exposure of electromagnetic energy on human tissues. The simulated and measured results of the proposed antenna exhibit wide bandwidth and radiation characteristics in both free space and human proximity.
\end{abstract}

\section{Introduction}

Body centric communications (BCC), a subpart of Body Area Networks (BAN), is one of its most active and potential research fields. Preeminence of health care and entertainment has made body centric communication an active research topic [1]. The proliferation of body centric communication applications and increase in demand for compact size and higher data rates have lead the researcher to focus on wide band antennas with compact size, low price, high gain, and good radiation characteristics. In the year 2002, Federal Communication Commissions (FCC) declared an ultrawide band spectrum ranging from $3.1 \mathrm{GHz}$ to $10.6 \mathrm{GHz}$ with bandwidth of $7.5 \mathrm{GHz}$ as unlicensed spectrum [2]. This wide band spectrum is a better choice for BCC applications as it provides high data rate with wide bandwidth and low power spectral density of $-41.3 \mathrm{dBm} / \mathrm{MHz}$ along with the advantage of low interference with existing narrow band devices in UWB spectrum. Various methods and design constraints of the planar UWB antennas and their miniaturizing techniques have been explained in [3-8]. BCC is broadly classified into three groups: on-body, off-body, and in-body communications [9]. High dielectric constant, lossy, and coupled nature of the human tissues have significant impact on antenna performance, which in turn degrades the antenna characteristics [9-12]. To design an antenna with UWB performance in presence of human tissue is a highly challenging and difficult task [13-15]. These antennas must satisfy fundamental requirements like low cost, low profile, and directive radiation pattern. Various UWB antennas are designed and presented for wearable applications in [16-22]. To protect the human body from electromagnetic exposure, SAR values within acceptable range, and as specified by various regulating bodies like FCC, IEEE, and so forth [23, 24], must be maintained by wearable antennas.

In this paper, a low profile pentagonal shaped planar monopole antenna is presented with wide bandwidth from $2.9 \mathrm{GHz}$ to $11 \mathrm{GHz}$. This antenna exhibits good frequency and time domain characteristics appropriate for BCC. This antenna can be easily integrated because of its compact dimensions for wearable applications. In the present study, antenna performance characteristics are investigated (i) in free space and (ii) on three-layered dispersive tissue equivalent phantom model. The proposed pentagonal monopole 


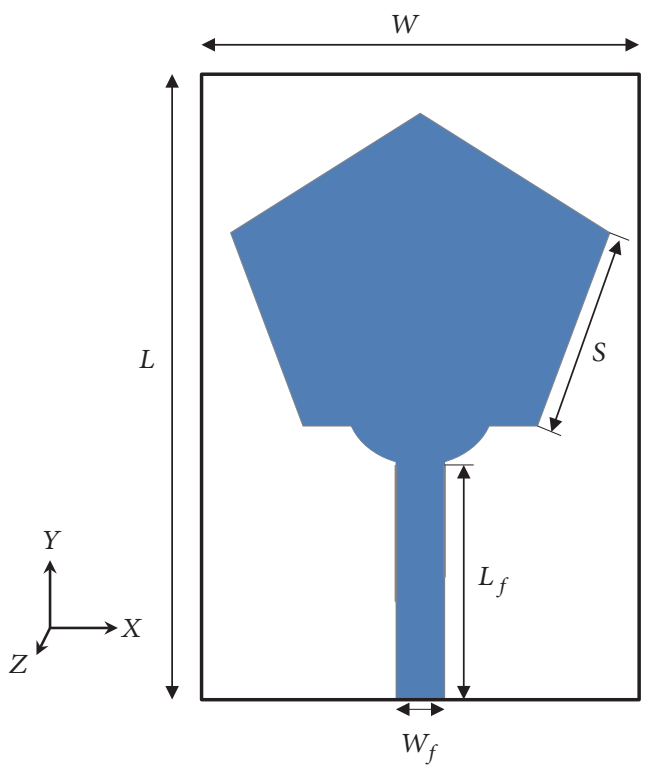

(a)

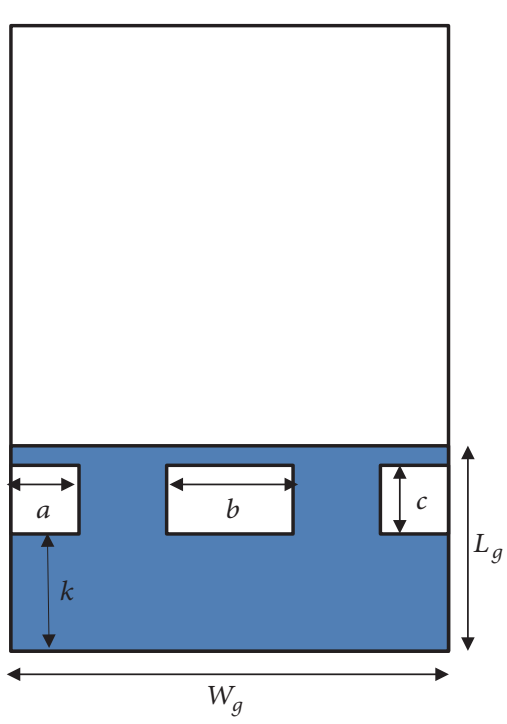

(b)

FIGURE 1: Geometry of the antenna: (a) front view and (b) bottom view.

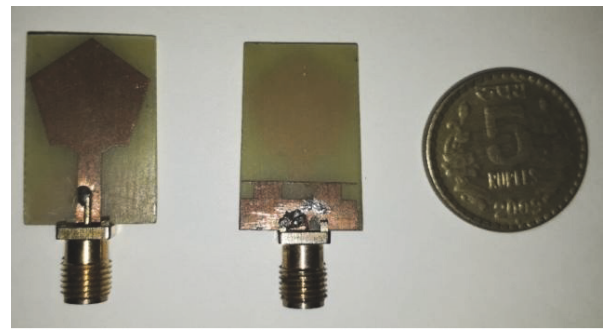

Figure 2: Fabricated prototype of the antenna with front and bottom views.

(PM) antenna design and simulations are carried out in HFSS and CST commercial electromagnetic software to evaluate frequency and time domain characteristics.

\section{Antenna Design}

The proposed PM antenna is designed and presented for UWB wearable applications as shown in Figure $1[15 \mathrm{~mm}$ $\times 25 \mathrm{~mm}$ ]. It consists of a pentagonal shaped radiator with $50 \mathrm{ohm}$ feed line and a partially defected ground plane with rectangular slots. In Figure 2, a fabricated prototype of this antenna, using low cost FR4 substrate with thickness of $1.6 \mathrm{~mm}$, is presented for experimental evaluation purpose.

Bandwidth of the proposed antenna depends upon the feed line width, edge of the pentagonal radiator, and partially defected ground with rectangular slots. The width of the feed line " $W_{f}$ " is adjusted to match the input impedance of $50 \mathrm{ohm}$ SMA connector.

The proposed antenna bandwidth can be increased with variations made in the ground plane and feed structure. The lower limit of the antenna bandwidth can be improved by varying the feed line width and feed gap space. Upper limit of this antenna structure can be improved by inserting the slots in ground plane and inserting a flared edge at the feed line connecting to the pentagonal radiator. In the proposed antenna design, the shape of the patch, feed line with flared edge structure, and partial ground with rectangular slots enhance the bandwidth and inflate radiation pattern normal to the patch surface. The dimensions of the proposed antenna structure are $L=25 \mathrm{~mm}, W=15 \mathrm{~mm}, S=9.3 \mathrm{~mm}, L_{f}=$ $9.2 \mathrm{~mm}, W_{f}=2.8 \mathrm{~mm}, L_{g}=6.25 \mathrm{~mm}, W_{g}=15 \mathrm{~mm}, k=4 \mathrm{~mm}$, $a=2 \mathrm{~mm}, b=4 \mathrm{~mm}$, and $c=2 \mathrm{~mm}$.

\section{Parametric Analysis of PM Antenna}

Parametric analysis of the PM antenna design with various design parameters are simulated using HFSS software. Here, to improve the PM antenna performance, the following parameters are investigated: (i) feed line with flaring structure, (ii) gap between ground plane and radiator, (iii) feed line width, and (iv) effect of edge and center slots inserted in the ground plane. Elaborated analyses of the abovementioned parameters are given below.

3.1. Effect of Flaring Structure. Introduction of flaring has improved the impedance bandwidth by increasing the upper 

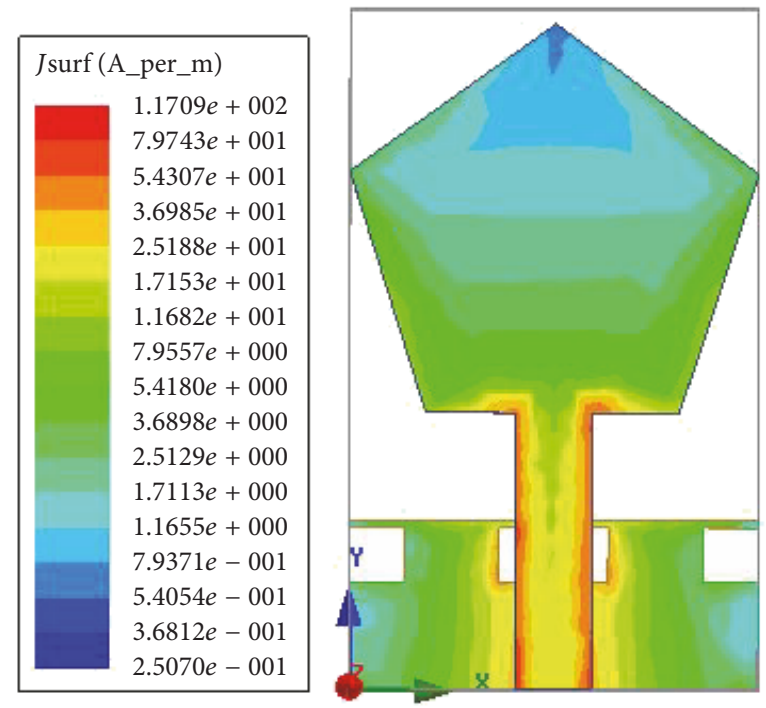

(a)
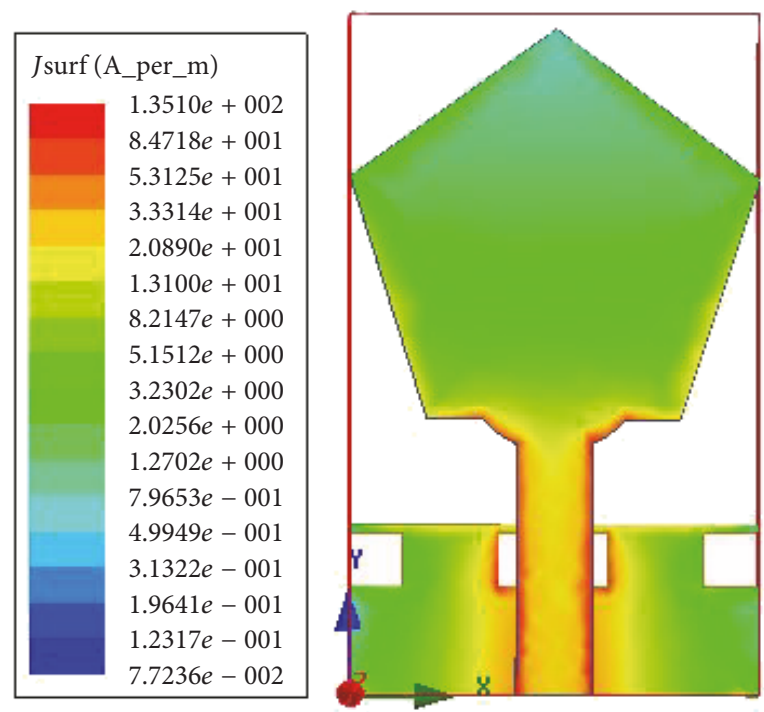

(c)
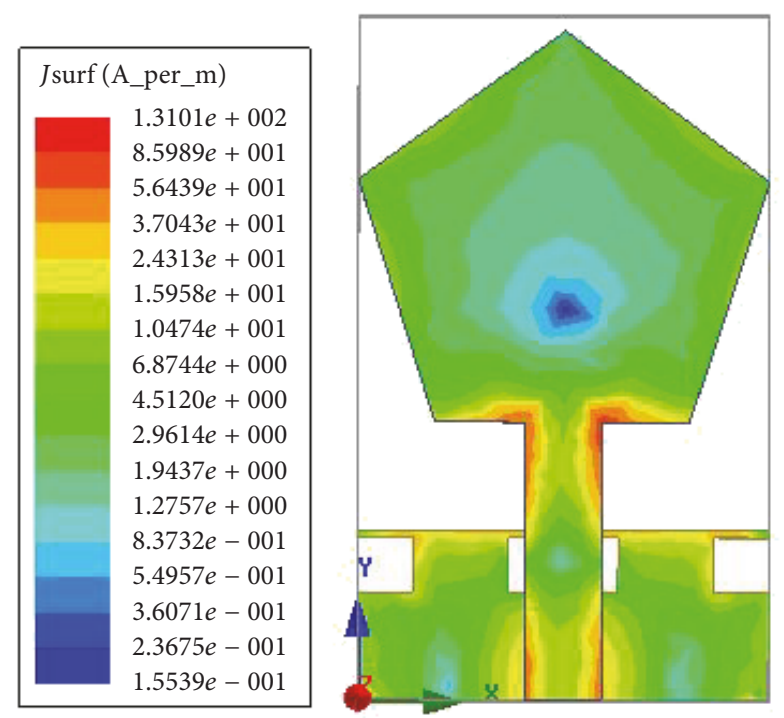

(b)
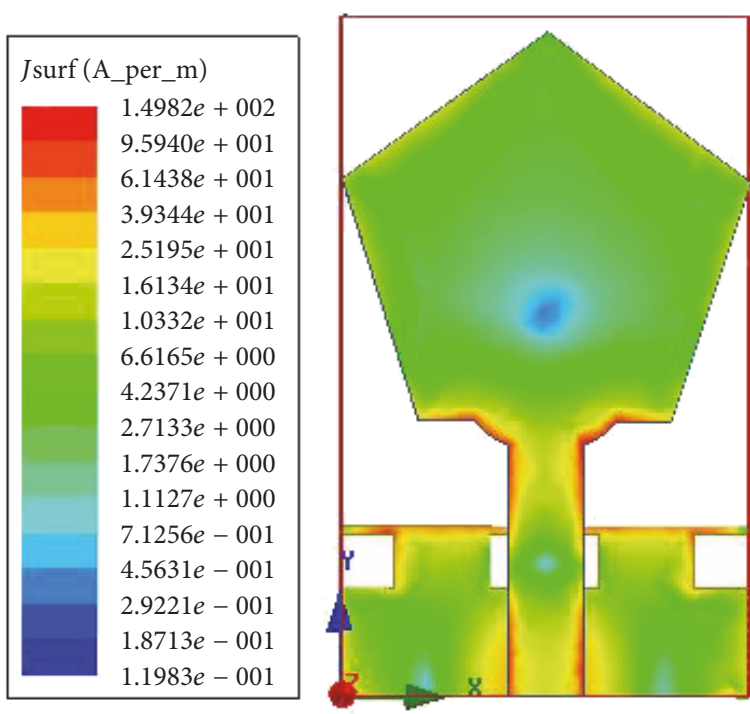

(d)

Figure 3: Surface current distributions of PM antenna: without flared feed at (a) $3.1 \mathrm{GHz}$ and (b) $10.5 \mathrm{GHz}$ and with flared feed at (c) $3.1 \mathrm{GHz}$ and (d) $10.5 \mathrm{GHz}$.

edge of the frequency spectrum. This is due to the increase in surface current distribution along the patch, which is shown in Figure 3. This can be clearly observed from Figure 4, where a clear vision of return loss between antenna with and without flaring is presented. On the other hand, it can also be observed that the effect on the lower edge of the frequency is negligible.

3.2. Effect of Feed Gap on Bandwidth. Feed gap is a crucial parameter, which can be used to reduce the coupling currents between the top edge of ground plane and bottom edge of the patch radiator. This gap has shown a significant change in impedance bandwidth. Bandwidth variation with different feed gaps $(0.95 \mathrm{~mm}, 1.95 \mathrm{~mm}, 2.95 \mathrm{~mm}$, and $3.95 \mathrm{~mm})$ has been investigated and an optimum value is chosen from the analysis shown in Figure 5. This analysis shows that gap variation affects both higher and lower frequencies ranging from $2 \mathrm{GHz}$ to $12 \mathrm{GHz}$. Among these variations, $2.95 \mathrm{~mm}$ is selected for providing better and wide impedance bandwidth.

3.3. Effect of Feed Line Width $\left(W_{f}\right)$. Variation in the feed line width $\left(W_{f}\right)$ is used to match the impedance of patch radiator. Here, the effect of $W_{f}$ on the lower and upper edge frequencies is assessed and presented in Figure 6. From this figure, it is clear that $W_{f}<2.8 \mathrm{~mm}$ has improved the lower edge frequency while showing negative impact on the upper edge frequency. On the other hand, $W_{f}>2.8 \mathrm{~mm}$ has shown positive effect on upper edge frequencies and negative impact on lower edge frequencies. At $W_{f}=2.8$, the upper and 


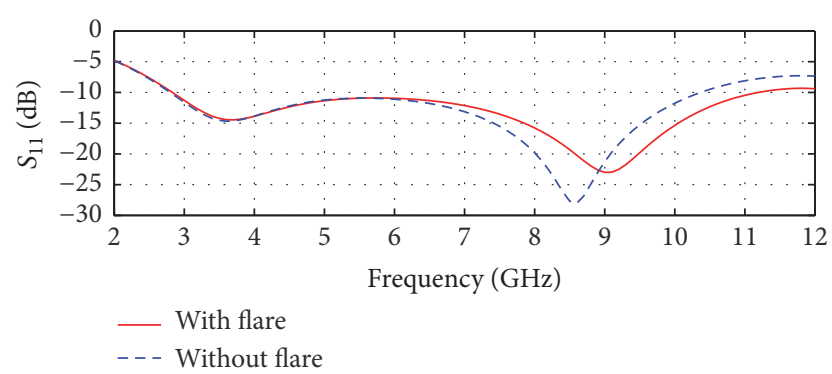

FIGURE 4: Effect of flaring structure on impedance bandwidth.

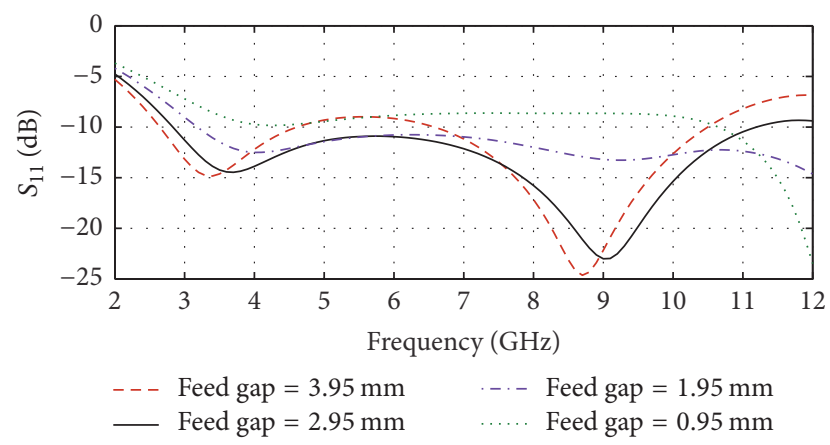

FIGURE 5: Effect of feed gap variation on impedance bandwidth.

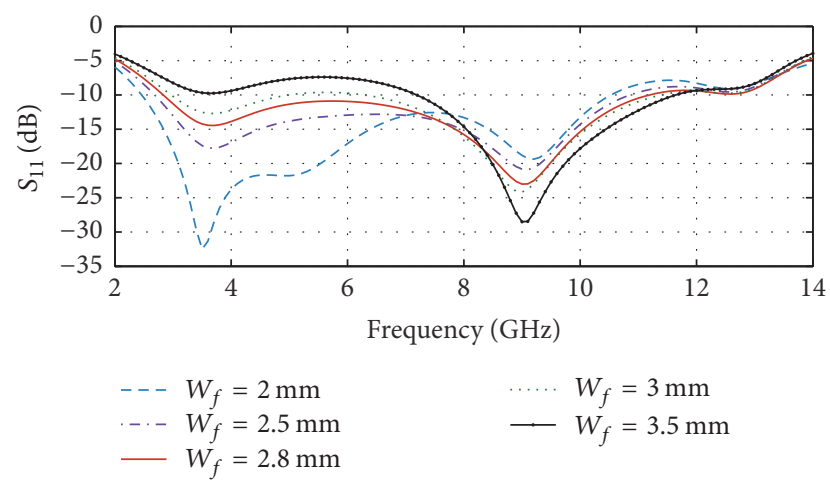

FIGURE 6: Effect of feed width on impedance bandwidth.

lower edge frequencies lie in the complete UWB frequency range. Hence, the optimum value for the feed line width is considered as $W_{f}=2.8 \mathrm{~mm}$.

3.4. Effect of Ground Plane Slots on Impedance Bandwidth. In this subsection, clear analyses of the effect of ground plane slot widths and locations are presented. Optimum slot widths and locations are taken from the analysis and are presented here along with the justification.

3.4.1. Edge Slot Width (a). The high frequency response has been improved with inclusion of rectangular slots in the ground plane. This has also increased the current distribution around the slots in the ground plane as shown in Figure 3. By increasing the edge slots width (a) from $1.5 \mathrm{~mm}$ to $3.5 \mathrm{~mm}$ with step size of $0.5 \mathrm{~mm}$ return loss characteristics are

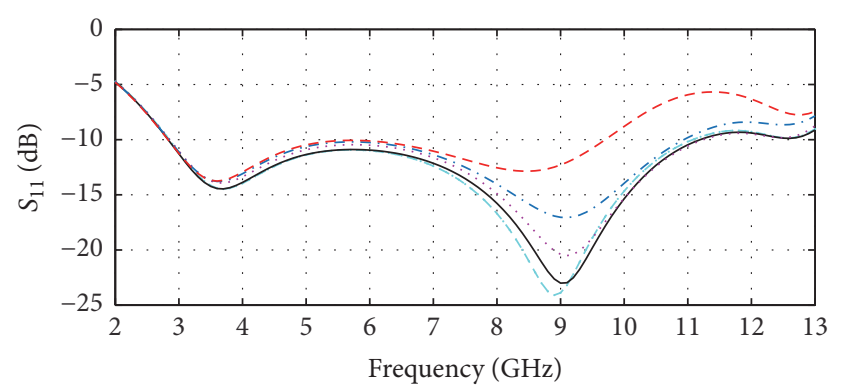

Edge slot width $a=1.5 \mathrm{~mm}$
Edge slot width $a=2.0 \mathrm{~mm}$
… Edge slot width $a=2.5 \mathrm{~mm}$
-. Edge slot width $a=3.0 \mathrm{~mm}$
- Edge slot width $a=3.5 \mathrm{~mm}$

Figure 7: Effect of edge slots width on impedance bandwidth.

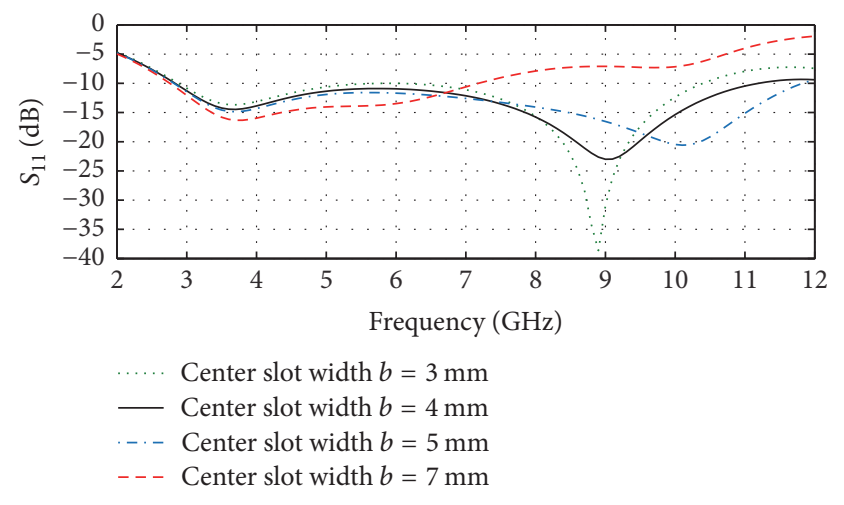

Figure 8: Effect of center slot width on impedance bandwidth.

measured and are presented in Figure 7. From this figure, it can be observed that the highest frequency of operation has improved only when the width of slots is kept below $3 \mathrm{~mm}$. For wider edge slots, that is, $3.5 \mathrm{~mm}$, the advantage is lost. Hence, the optimal value of the edge slot width is considered as $a=3 \mathrm{~mm}$.

3.4.2. Center Slot Width (b). To further enhance the bandwidth, a center slot has been introduced in the ground plane. It has shown an optimistic performance. With increment in width of the center slot, upper edge of the frequency spectrum has been affected. These effects are presented in Figure 8, with variation in center slot width from $3 \mathrm{~mm}$ to $7 \mathrm{~mm}$. The return loss variations show that the upper edge frequency is increased at $b=4 \mathrm{~mm}$ and $5 \mathrm{~mm}$ and showing negative impact on the other values. Hence, the optimum center slot width is considered as $b=4 \mathrm{~mm}$.

3.4.3. Effect of Slots Location. The impedance bandwidth variations with respect to the location of slots in the ground plane are investigated and presented in Figure 9. It is clearly observed that, by moving the slots from lower edge of ground plane to top, there is a significant improvement in higher operating frequencies. The optimal value of the slots location to enhance bandwidth is considered as $k=4 \mathrm{~mm}$. 


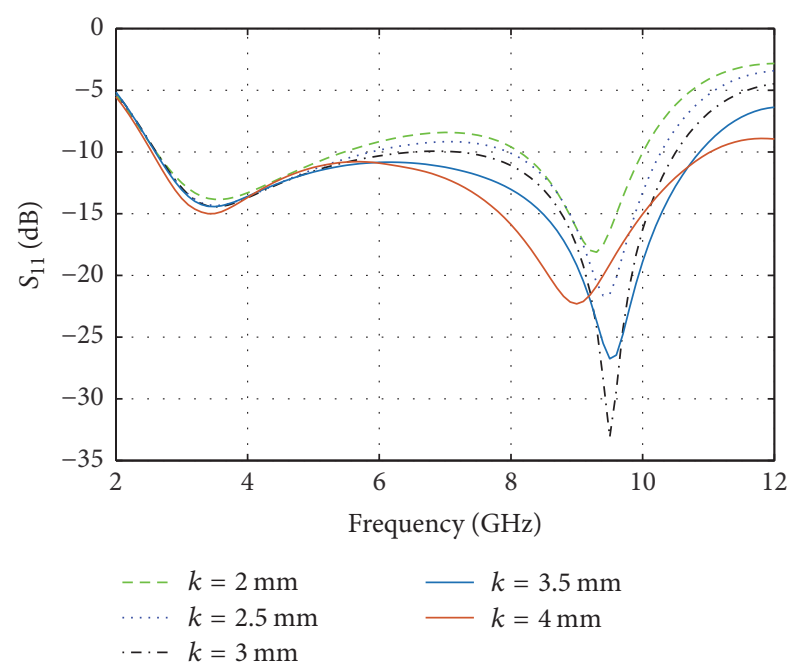

FIGURE 9: Effect of slots location on impedance bandwidth.

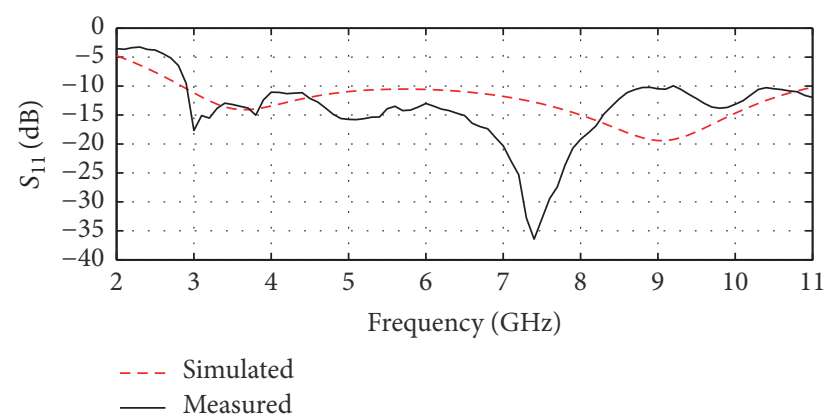

FIGURE 10: Simulated and measured reflection coefficients of PM antenna.

\section{Results and Discussions}

The results of PM antenna over the bandwidth range of $2.9 \mathrm{GHz}$ to $11 \mathrm{GHz}$ are analysed and discussed in this section. The PM antenna exhibits wide impedance matching performance with good radiation characteristics. In order to observe the PM antenna performance in free space as well as on phantom model, various performance characteristics are evaluated and presented below.

4.1. Performance Analysis of PM Antenna in Free Space. The return loss characteristics are measured with the help of programmable network analyser (PNA). The measured reflection coefficient $\left(S_{11}\right)$ in Figure 10 shows good agreement with simulated $S_{11}$ and provides a wide range of impedance bandwidth from $2.9 \mathrm{GHz}$ to $11 \mathrm{GHz}$.

Time domain analysis of UWB antennas represents the phase linearity and distortion in the received pulses. In UWB pulse transmission, linear phase variation provides low pulse distortion in received signals. The pulse distortion can be analysed with the help of group delay and fidelity factor. Hence, linear phase variation in $S_{21}$ or constant group delay is required for better transmission in UWB systems. From

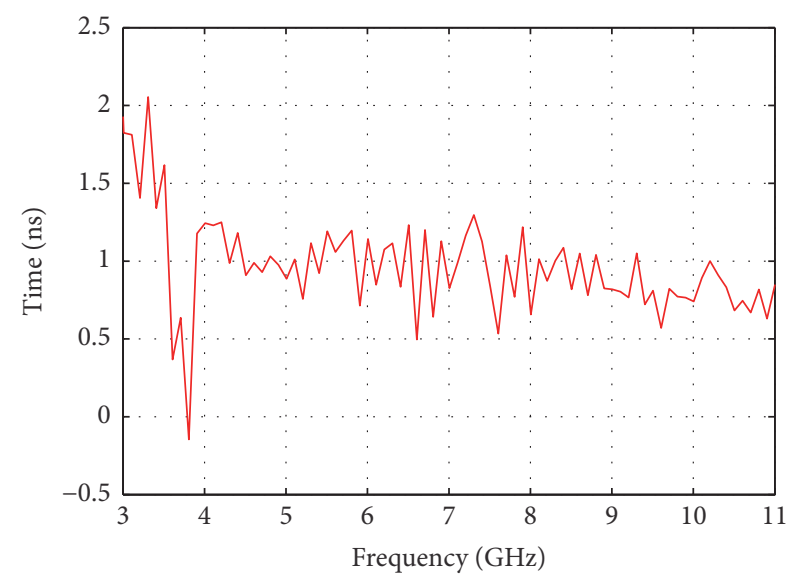

FIGURE 11: Measured group delay.

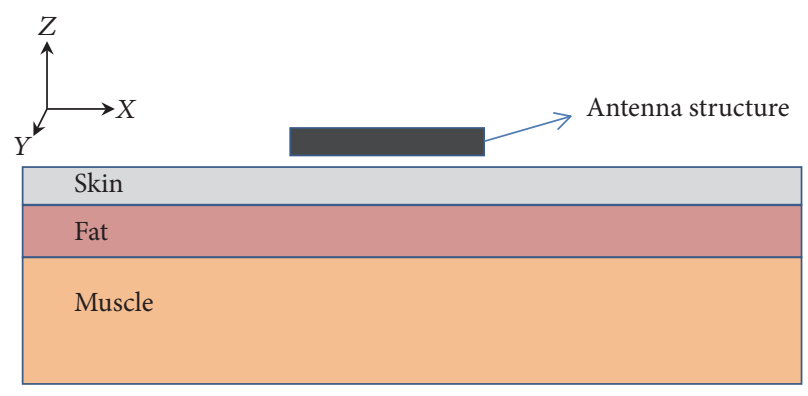

FIGURE 12: Dispersive phantom model with three layers.

Figure 11, it is clear that the proposed PM antenna shows constant group delay, This in turn leads to less distortion in pulse transmission. The distance between the two antennas is considered as 0.3 meters.

4.2. Results Analysis on Dispersive Phantom Model. Human tissues are lossy and dispersive in nature at higher frequencies. Due to the electromagnetic properties of tissues, antenna characteristics like resonant frequency, bandwidth, and radiation pattern are drastically affected. In the proximity of human body, antenna performance degrades. This is not suitable for the required applications. In general, increase in frequency causes decrease in tissue dielectric constant and increase in conductivity and loss tangent [25-27]. For wearable applications, antennas need to be designed with characteristics that do not vary a lot in the presence of tissues.

A tissue equivalent phantom model is constructed with three layers (skin, fat, and muscle) in HFSS and CST software as shown in Figure 12. This phantom model is rectangular shaped with fat, skin, and muscle layers with size of $80 \mathrm{~mm}$ $\times 40 \mathrm{~mm}$ and thicknesses of $2 \mathrm{~mm}, 5 \mathrm{~mm}$, and $30 \mathrm{~mm}$, respectively [27]. Debye equation presented in (1) is used to calculate the electrical properties of skin, fat, and muscle layers in the entire UWB frequency range with step size of $100 \mathrm{MHz}$. For each frequency variation, corresponding dielectric constant and loss tangent values are taken based on Debye equation over the UWB frequency span. For a tissue, to 
TABLE 1: Dielectric properties of human tissue at $5 \mathrm{GHz}$ frequency.

\begin{tabular}{lcccc}
\hline Tissue type & Permittivity $\left(\varepsilon_{r}\right)$ & Loss tangent & $\begin{array}{c}\text { Conductivity }(\sigma) \\
\text { S/m }\end{array}$ & $\begin{array}{c}\text { Mass density }(\rho) \\
\mathrm{kg} / \mathrm{m}^{3}\end{array}$ \\
\hline Skin (dry) & 36.6 & 0.288 & 2.35 & 1109 \\
Fat & 5.13 & 0.16 & 0.18 & 911 \\
Muscle & 50.8 & 0.267 & 3.03 & 1090 \\
\hline
\end{tabular}

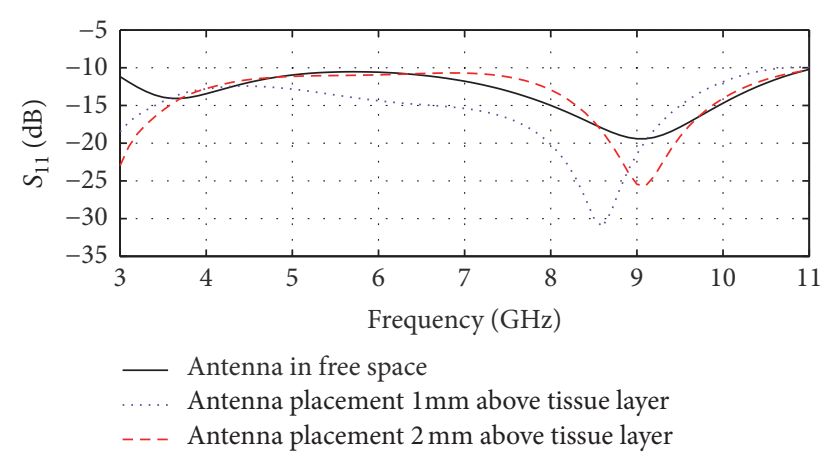

FIGURE 13: PM antenna return loss characteristics on dispersive phantom model.

have a greater impact on microwave signals, permittivity and water content play a major role [25]. In Table 1, the electrical characteristics of tissue layers are presented for $5 \mathrm{GHz}$ [27]. From this table, it can be observed that the permittivity of skin and muscle layers is high when compared to fat tissue. The water content present in skin and muscle layers is more than that of fat. Hence, skin and muscle layers play a major role in signal absorption.

$$
\varepsilon_{\tau}=\varepsilon_{\infty}+\frac{\varepsilon_{s}-\varepsilon_{\infty}}{1+j \omega \tau}-j \frac{\sigma_{s}}{\omega \varepsilon_{0}},
$$

where " $\varepsilon_{\tau}$ " is complex permittivity, " $\sigma_{s}$ " is conductivity, " $\varepsilon_{0}$ " is free space permittivity, " $\omega$ " is angular frequency, " $\varepsilon_{s}$ " is static permittivity, " $\varepsilon_{\infty}$ " is optical permittivity, and " $\tau$ " is relaxation time.

Return loss characteristics are simulated for the proposed PM antenna in HFSS software for the following considerations: (i) antenna in free space and (ii) antenna placed at a distance of $1 \mathrm{~mm}$ and $2 \mathrm{~mm}$ above the tissue layer. These results, presented in Figure 13, show that PM antenna is performing well in the proximity of the human tissues. Figure 14 shows the experimental setup for measuring reflection coefficient on two different scenarios. Return loss characteristics are proposed for PM antenna on human shoulder and hand with $1 \mathrm{~mm}$ gap and the corresponding impedance bandwidth observations are presented in Figure 15. From these observations, the proposed PM antenna shows acceptable performance with wide bandwidth ranging from $2.9 \mathrm{GHz}$ to $11 \mathrm{GHz}$.

4.3. Gain and Radiation Efficiency. Peak gain variations of the proposed PM antenna are evaluated in CST MW STUDIO as a function of distance from the tissue model and are presented in Figure 16. In presence of dispersive phantom with small separation ( $1 \mathrm{~mm}$ distance), the maximum gain values are less than the free space gain values due to strong coupling. If the distance is further increased, peak gain values also increase. In some cases peak gain values exceeded the free space gain values due to strong reflections from the phantom model.

In close proximity of human tissues, antennas exhibit very poor radiation efficiencies due to high power absorption in the tissues. Its efficiency increases with increase in separation distance [28]. Similarly the proposed PM antenna radiation efficiency is also affected by separation distance between the antenna and phantom model as shown in Figure 17. By increasing this separation distance, gain and efficiency also increase.

Radiation patterns for the proposed PM antenna in free space and dispersive tissue model with $1 \mathrm{~mm}$ separation are shown in Figure 18. From these plots, it can be observed that front to back ratio in the presence of phantom tissue is higher when compared to that of the free space pattern. This is due to strong reflection from the flat dispersive phantom tissue layers designed with high dielectric constants $[15,16]$. It is also evident from Figure 18 that when in close proximity to human tissues, $E$-plane patterns are affected more than the $H$-plane patterns.

4.4. SAR Assessment on Dispersive Phantom. SAR is used to investigate the electromagnetic energy absorption in human body tissues under reactive near fields. SAR is calculated as

$$
\operatorname{SAR}=\frac{\sigma}{\rho}|E|^{2},
$$

where $\rho$ is density and $\sigma$ is conductivity of the corresponding tissue material and $|E|^{2}$ is the RMS value of induced electric field.

SAR values depend on the antenna distance from the phantom as well as on the tissues dielectric constant [29]. The average $1 \mathrm{~g}$ SAR of PM antenna has been investigated with different gaps $(1 \mathrm{~mm}, 5 \mathrm{~mm}$, and $10 \mathrm{~mm})$, on a dispersive phantom model designed with size of $80 \mathrm{~mm} \times 80 \mathrm{~mm} \times$ $33 \mathrm{~mm}$, being presented in Table 2 . Input power of $1 \mathrm{~mW}$ is applied in HFSS software to evaluate the SAR values. It is observed that the distance between the antenna and flat dispersive phantom will have a great influence on the radiation pattern as well as on energy absorbed by the tissues. Among the three tissue layers, skin tissue has absorbed more energy than the other tissues due to its high permittivity. From Table 2, the obtained maximum average SAR value is 
TABLE 2: 1 gram averaged peak SAR values with different antenna distances from the phantom.

\begin{tabular}{|c|c|c|c|c|c|c|c|c|c|}
\hline \multirow{3}{*}{ Frequency $(\mathrm{GHz})$} & \multicolumn{9}{|c|}{ SAR mw/kg } \\
\hline & \multicolumn{3}{|c|}{$1 \mathrm{~mm}$} & \multicolumn{3}{|c|}{$5 \mathrm{~mm}$} & \multicolumn{3}{|c|}{$10 \mathrm{~mm}$} \\
\hline & Skin & Fat & Muscle & Skin & Fat & Muscle & Skin & Fat & Muscle \\
\hline 3.1 & 129 & 31.2 & 111.9 & 52 & 8.35 & 38.8 & 25.5 & 2.71 & 14.7 \\
\hline 6 & 386 & 39.6 & 118.2 & 220 & 1.7 & 56.9 & 99.6 & 6.46 & 19.1 \\
\hline 10.5 & 480 & 46.7 & 37.5 & 110 & 8.3 & 8.6 & 36.5 & 2.1 & 1.63 \\
\hline
\end{tabular}

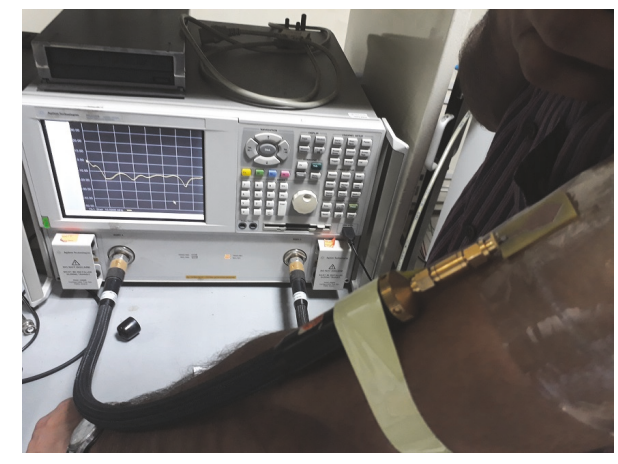

(a) On shoulder

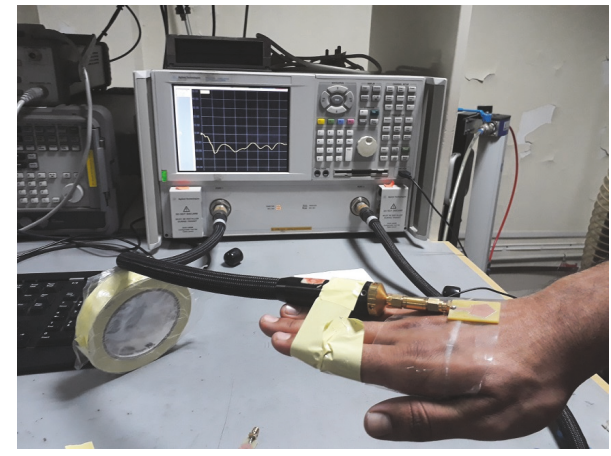

(b) On hand

FIGURE 14: Experimental setup for reflection coefficient measurement.

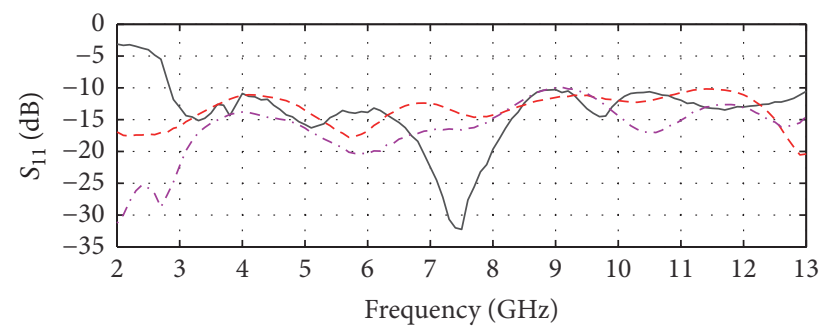

_ In free space

- - - On shoulder

.... On hand

Figure 15: Measured reflection coefficients comparison of the PM antenna.

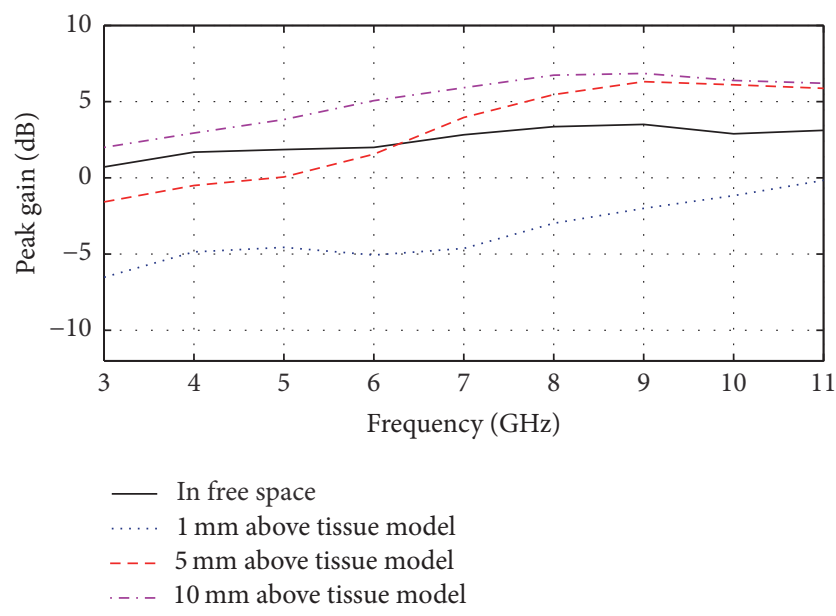

FIGURE 16: Peak gain of the proposed PM antenna.
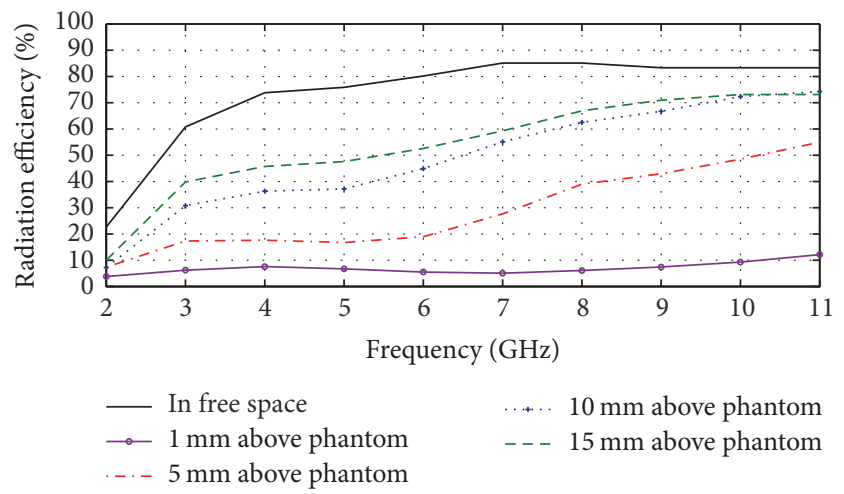

FIGURE 17: Radiation efficiency.

$0.48 \mathrm{~W} / \mathrm{kg}$ (1 $\mathrm{g}$ averaging mass). This is well under the public RF safety exposure limit of $1.6 \mathrm{~W} / \mathrm{kg}$, specified by FCC [23].

\section{Conclusion}

A low profile PM antenna is designed and demonstrated for body centric communications. This antenna exhibits good frequency domain and time domain characteristics. The impedance matching characteristics of this antenna in free space and on dispersive phantom model show excellent agreement with measured reflection coefficient on human shoulder and hand in UWB frequency range. This antenna also meets the low SAR value specifications prescribed by FCC. Hence, this antenna can be an excellent choice for wearable and UWB localization applications. 


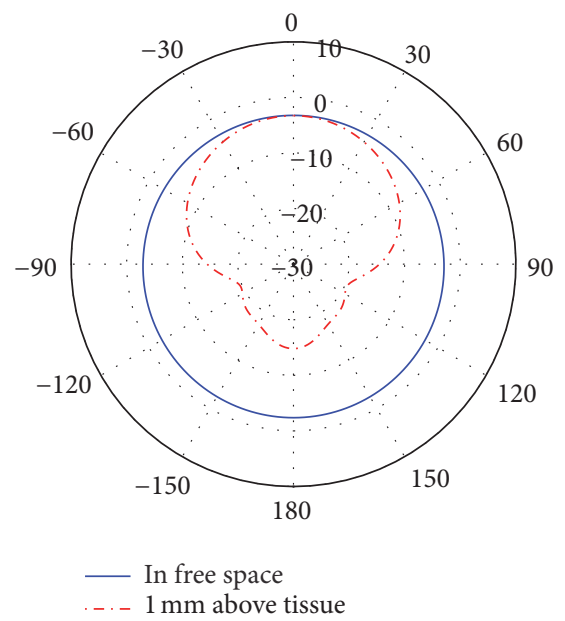

(a) E-plane at $3.1 \mathrm{GHz}$

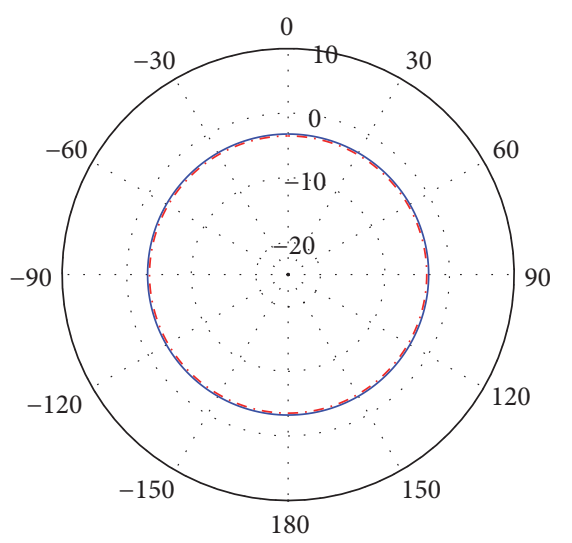

_. In free space
... $1 \mathrm{~mm}$ above tissue

(d) $H$-plane at $3.1 \mathrm{GHz}$

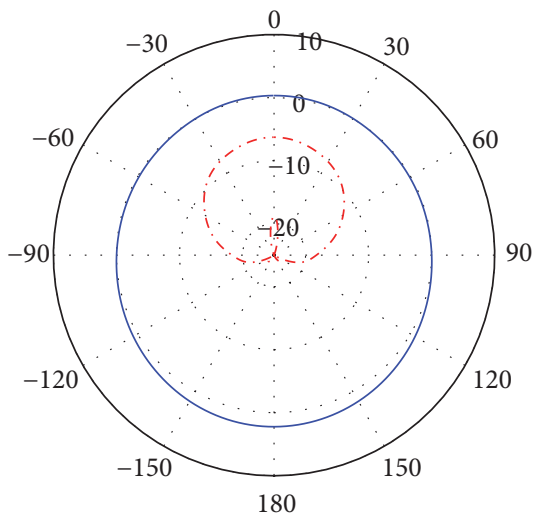

- In free space

-. - $1 \mathrm{~mm}$ above tissue

(b) E-plane at $6 \mathrm{GHz}$

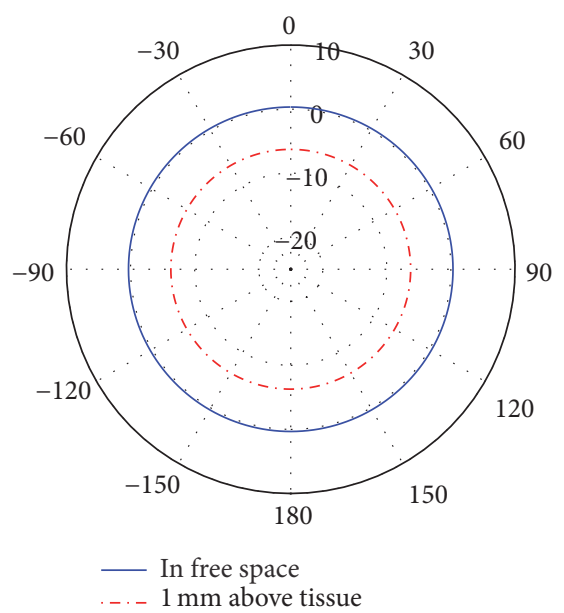

(e) $H$-plane at $6 \mathrm{GHz}$

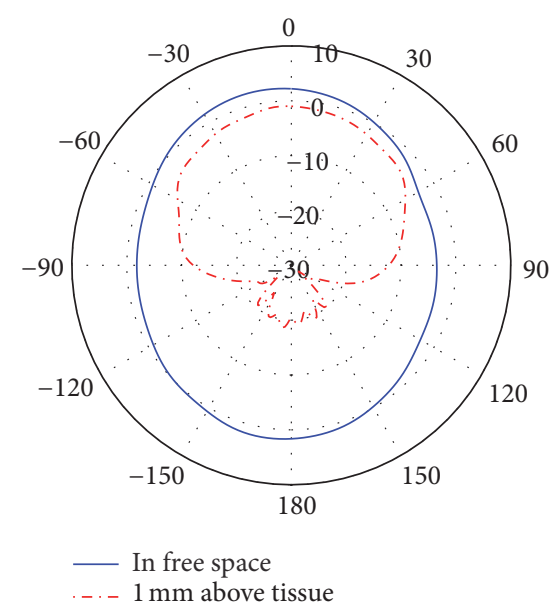

(c) E-plane at $10.5 \mathrm{GHz}$

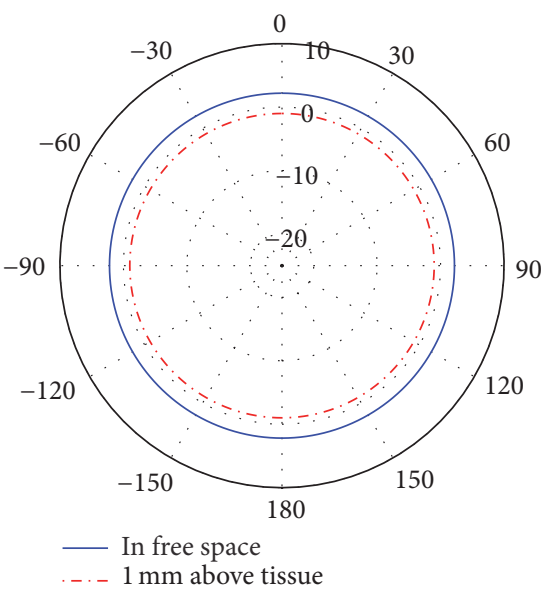

(f) $H$-plane at $10.5 \mathrm{GHz}$

FIGURE 18: Radiations patterns without and with phantom model.

\section{Conflicts of Interest}

All authors declare that there are no conflicts of interest regarding this manuscript.

\section{References}

[1] X. Li, Body Matched Antennas for Microwave Medical Applications, vol. 72, KIT Scientific Publishing, 2014.

[2] "Revision of Part 15 of the Commission's Rules Regarding UltraWideband Transmission Systems. First Report and Order," Tech. Rep. ET Docket 98-153, FCC 02-48, Federal Communications Commission, 2002.

[3] R. Garg, Microstrip Antenna Design Handbook, Artech House, 2001.

[4] K. P. Ray, "Design aspects of printed monopole antennas for ultra-wide band applications," International Journal of Antennas and Propagation, vol. 2008, Article ID 713858, 8 pages, 2008.

[5] C. Gupta Kuldip and B. Abdelaziz, Microstrip Antenna Design, Artech House, 1988.

[6] T. Zwick et al., Ltra-Wideband RF System Engineering, Cambridge University Press, 2013.
[7] A. K. Skrivervik, J.-F. Zürcher, O. Staub, and J. R. Mosig, "PCS antenna design: the challenge of miniaturization," IEEE Antennas and Propagation Magazine, vol. 43, no. 4, pp. 12-27, 2001.

[8] B. A. Kramer, C.-C. Chen, M. Lee, and J. L. Volakis, "Fundamental limits and design guidelines for miniaturizing ultrawideband antennas," IEEE Antennas and Propagation Magazine, vol. 51, no. 4, pp. 57-69, 2009.

[9] P. S. Hall and Y. Hao, Antennas and Propagation for BodyCentric Wireless Communications, Artech House, Norwood, MA, USA, 2006.

[10] T. Kumpuniemi, M. Hamalainen, K. Y. Yazdandoost, and J. Iinatti, "Human tissue type and volume effect on the on-body UWB antenna matchings," in Proceedings of the 10th International Symposium on Medical Information and Communication Technology, ISMICT 2016, Worcester, MA, USA, March 2016.

[11] P. Salonen, Y. Rahmat-Samii, and M. Kivikoski, "Wearable antennas in the vicinity of human body," in Antennas and Propagation Society International Symposium, IEEE, vol. 1, Monterey, CA, USA, 2004.

[12] A. Rahman, M. T. Islam, M. J. Singh, S. Kibria, and M. Akhtaruzzaman, "Electromagnetic Performances Analysis of an 
Ultra-wideband and Flexible Material Antenna in Microwave Breast Imaging: To Implement A Wearable Medical Bra," Scientific Reports, vol. 6, Article ID 38906, 2016.

[13] T. Takimoto, T. Onishi, K. Saito, M. Takahashi, S. Uebayashi, and K. Ito, "Characteristics of biological tissue equivalent phantoms applied to UWB communications," Electronics and Communications in Japan, Part I: Communications (English translation of Denshi Tsushin Gakkai Ronbunshi), vol. 90, no. 5, pp. 48-55, 2007.

[14] K. Maciej and G. Troester, "EM energy absorption in the human body tissues due to UWB antennas," Progress in Electromagnetics Research, vol. 62, pp. 261-280, 2006.

[15] T. Tuovinen et al., "Ultra wideband loop antenna on contact with human body tissues," IET Microwaves, Antennas \& Propagation, vol. 7, no. 7, pp. 588-596, 2013.

[16] V. Kumar and B. Gupta, "On-body measurements of SS-UWB patch antenna for WBAN applications," AEU - International Journal of Electronics and Communications, vol. 70, no. 5, pp. 668-675, 2016.

[17] A. Alomainy, Y. Hao, C. G. Parini, and P. S. Hall, "Comparison between two different antennas for UWB on-body propagation measurements," IEEE Antennas and Wireless Propagation Letters, vol. 4, no. 1, pp. 31-34, 2005.

[18] Q. H. Abbasi, M. U. Rehman, X. D. Yang, A. Alomainy, K. Qaraqe, and E. Serpedin, "Ultrawideband band-notched flexible antenna for wearable applications," IEEE Antennas and Wireless Propagation Letters, vol. 12, pp. 1606-1609, 2013.

[19] R. Bharadwaj, S. Swaisaenyakorn, C. G. Parini, J. Batchelor, and A. Alomainy, "Localization of wearable ultrawideband antennas for motion capture applications," IEEE Antennas and Wireless Propagation Letters, vol. 13, pp. 507-510, 2014.

[20] T. S. P. See and Z. N. Chen, "Experimental characterization of UWB antennas for on-body communications," IEEE Transactions on Antennas and Propagation, vol. 57, no. 4, pp. 866-874, 2009.

[21] E. Tahanian, "Very compact uwb antenna with group delay improvement," Serbian Journal of Electrical Engineering, vol. 12, no. 2, 2015.

[22] N. Chahat, M. Zhadobov, R. Sauleau, and K. Ito, "A compact UWB antenna for on-body applications," IEEE Transactions on Antennas and Propagation, vol. 59, no. 4, pp. 1123-1131, 2011.

[23] Evaluating Compliance with FCC Guidelines for Human Exposure to Radiofrequency Electromagnetic Fields, Fields, Radiofrequency Electromagnetic, 1997.

[24] "IEEE Recommended Practice for Measurements and Computations of Radio Frequency Electromagnetic Fields With Respect to Human Exposure to Such Fields, $100 \mathrm{kHz}-300 \mathrm{GHz}$," IEEE Std C95.3-2002, 126 pages, 2002.

[25] C. Gabriel, Compilation of the Dielectric Properties of Body Tissues at RF and Microwave Frequencies, King's College London, Dept of Physics, London, UK, 1996.

[26] S. Esther Florence, K. Malathi, and M. A. Gulam Nabi, "An Investigation of a Wearable Antenna Using Human Body Modelling," Applied Computational Electromagnetics Society Journal, vol. 29, no. 10, 2014.

[27] D. Andreuccetti, R. Fossi, C. Petrucci et al., "An Internet resource for the calculation of the dielectric properties of body tissues in the frequency range $10 \mathrm{~Hz}-100 \mathrm{GHz}$," IFAC-CNR, 1997.

[28] T. Tuovinen, M. Berg, K. Y. Yazdandoost, E. Salonen, and J. Iinatti, "Reactive near-field region radiation of planar UWB antennas close to a dispersive tissue model," in Proceedings of the 2012 Loughborough Antennas and Propagation Conference, LAPC 2012, Loughborough, UK, November 2012.

[29] Q. Wang and J. Wang, "SA and SAR analysis for wearable UWB body area applications," IEICE Transactions on Communications, vol. E92-B, no. 2, pp. 425-430, 2009. 


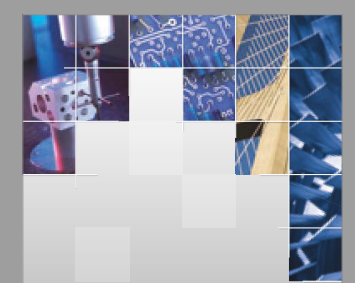

\section{Enfincering}
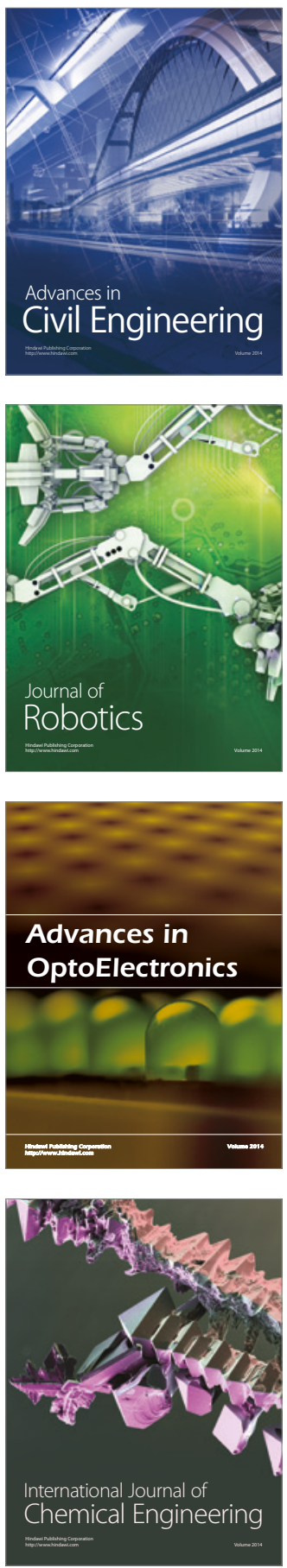

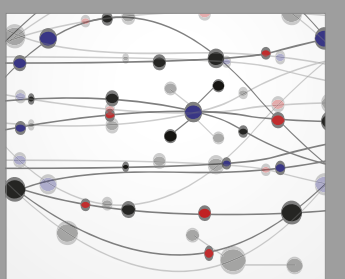

The Scientific World Journal

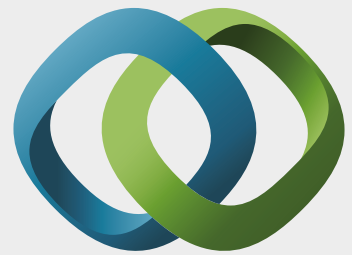

\section{Hindawi}

Submit your manuscripts at

https://www.hindawi.com
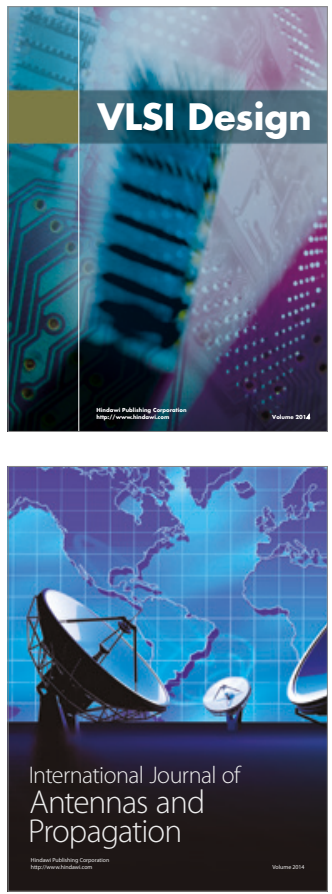

\section{Rotating}

Machinery
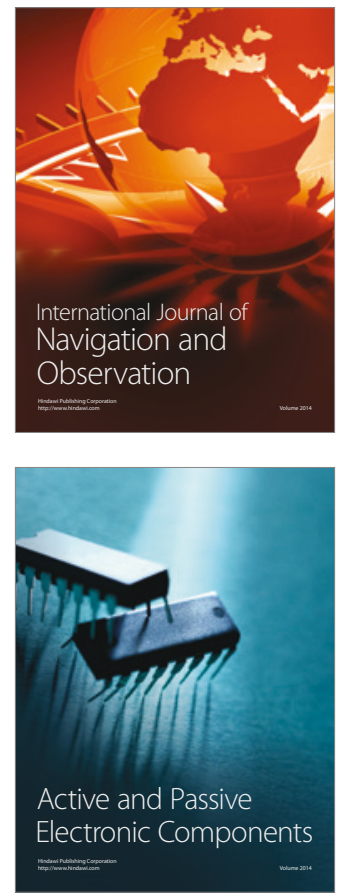
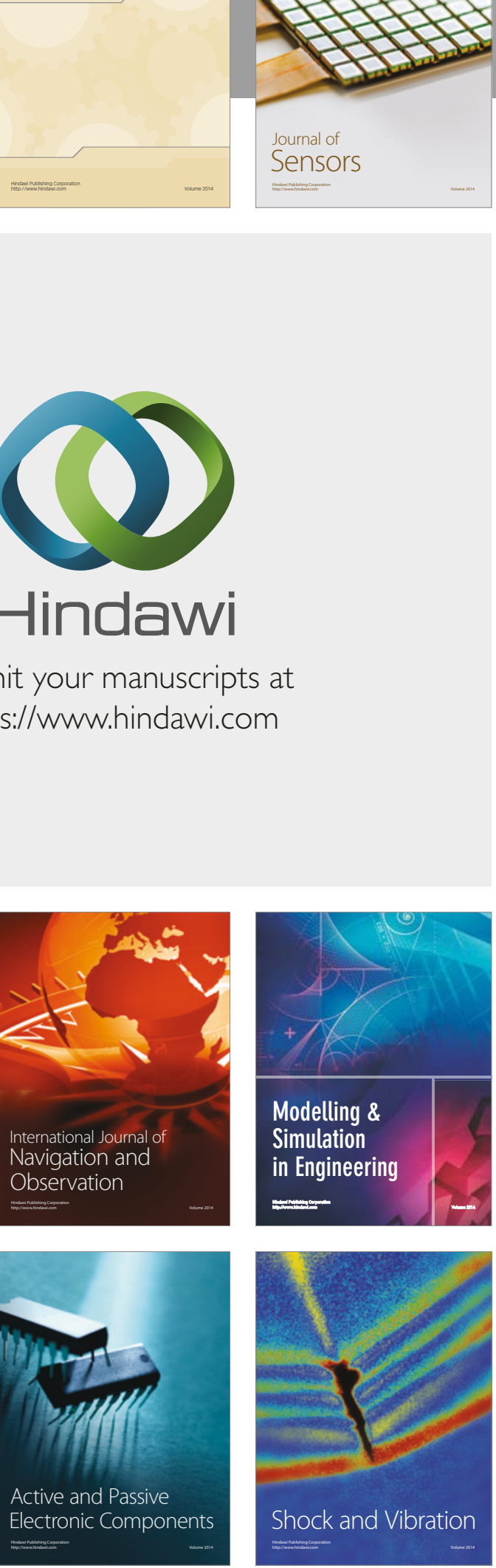
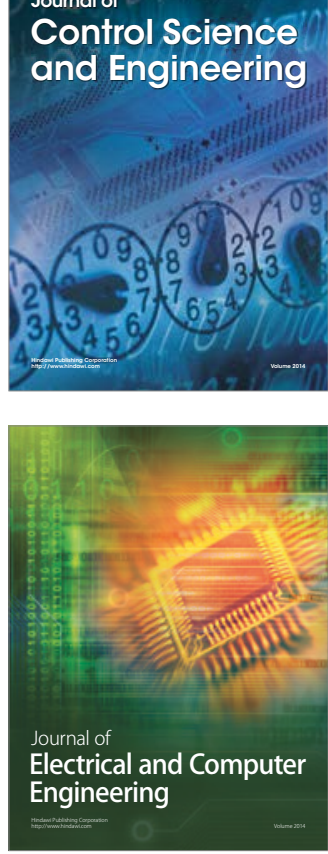

Distributed

Journal of

Control Science

and Engineering
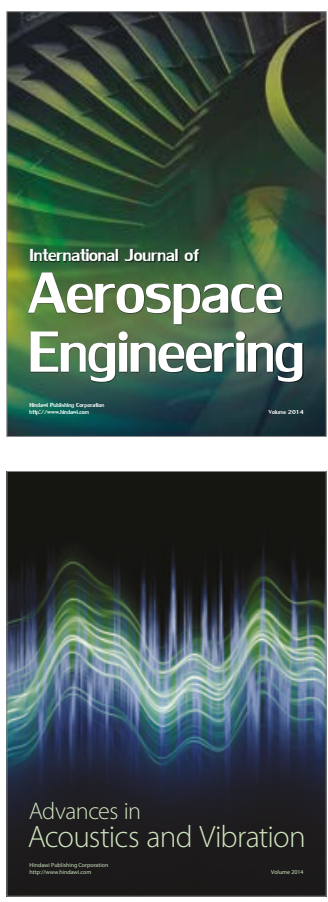

Sensor Networks 